\title{
Targets and technologies for climate control Guest Editorial
}

\author{
Valentina Bosetti • Bob van der Zwaan
}

Received: 29 May 2009 / Accepted: 9 June 2009 / Published online: 23 July 2009

(C) Springer Science + Business Media B.V. 2009

Special Issue

"The Economics of Climate Change: Targets and Technologies"

\section{Climatic Change}

In the community of climate policy makers 2009 will probably be remembered as the year in which the debate shifted decisively from questioning whether climate mitigation action ought to be undertaken to determining how extensive this action should be. Similarly in this year more pertinent than ever before became questions like how the required climate control efforts would need to be broken down among the countries at the origin of this global problem, what the long-term targets would have to look like, and what type of technologies should be employed to meet these targets. During the second half of the first decade of the 21st century several events led to this definite change: the publication of the Stern Review of the economics of climate change and the stream of reactions it generated (Stern et al. 2006), the attribution of the Nobel Peace Prize to $\mathrm{Al}$ Gore and the Intergovernmental Panel on Climate Change (Gore 2007; IPCC 2007), and the election in 2008 of a new US Administration with a favourable attitude towards significant climate action.

This special issue includes papers presented at the 2007 TranSust.Scan Conference on the "Economics of Climate Change and Sustainable Development".

\footnotetext{
V. Bosetti

Fondazione Eni Enrico Mattei, Sustainable Development,

C.so Magenta 63, 20123 Milano, Italy

B. van der Zwaan $(\varangle)$

Policy Studies Department, Energy research Centre of the Netherlands (ECN),

P.O. Box 56890, 1040 AW, Amsterdam, The Netherlands

e-mail: vanderzwaan@ecn.nl

B. van der Zwaan

Lenfest Center for Sustainable Energy, The Earth Institute, Columbia University, 500 West 120th Street, New York, NY 10027, USA
} 
These milestones culminated in the United Nations Framework Convention on Climate Change Conference in Copenhagen in December 2009 as first genuinely international effort to address the challenge of global warming with a firm, ambitious and effective agreement including all major parties involved.

The economics of climate change is the field of study concerned with the damages incurred as a result of climate change, the benefits of addressing the origins of climatic change and its environmental and economic consequences, and the costs of the means to avoid or mitigate these climate impacts. Of particular importance in this domain is the combined framing of the long-term climate management target, on the one hand, and the economic potential of concrete climate control technologies, on the other hand. The research related to these two themes-that is, choosing the appropriate climate target versus investigating the technological options and potential breakthroughs to reach these targets-are two faces of the same problem that are deeply intertwined. In order for policy decisions to be both meaningful and successful, they have to be investigated jointly and spelled out with great precision.

This special issue of Climatic Change, entitled "The Economics of Climate Change: Targets and Technologies", aims at doing just that. It consists of eight articles that discuss several distinct topics related to the two fundamental aspects of the climate change conundrum: how deep should a greenhouse gas emission cut be and with what means should we achieve this reduction? While some of the papers are more conceptual or theoretical in nature and others focus on more practical steps or concrete policy measures, all provide fundamental insight into the nature of the climate change problem and deliver input for the necessary policy making process. We believe that the points raised and arguments described in each of the eight contributions to this special issue constitute essential material for specifying the details of a global climate control agreement over the coming years. We strongly urge policy makers to account for the main findings reported in this special issue, and to proceed informing climate negotiations with the expertise of these and other scientists. The latter have as task and responsibility to adequately explain their ongoing research endeavours to the policy making community.

The first three papers deal with the issue of targets, timing of action and related uncertainties. Heal (2009) attempts to answer the question what we have learned from the outpouring of literature as a result of the Stern Review of the economics of climate change. His answer is unambiguous: a lot. In his paper he concludes that the model and parameter space of climate change economics has now much more thoroughly been explored. He rightly observes that the Stern Review has catalyzed a fundamental rethinking of the economic case for action on climate change. Today we are in a position to give conditions that are sufficient to provide a case for strong action, but we need more work before we have a fully satisfactory account of the relevant economics. In particular, we need to understand better how climate change affects natural capital — the natural environment and the ecosystems comprising itand how this in turn affects human welfare.

Bosetti et al. (2009) analyse the economic implications of delaying mitigation and compute the optimal abatement strategy to cope with an uncertain future climate target. Their results point to short-term inaction as the key determinant for the economic costs of ambitious climate policies. They also demonstrate that an effective hedging strategy exists that could minimize the costs associated with prevailing climate policy uncertainty over the global stabilisation target: a short-term moderate 
climate policy would constitute a good means to reduce the costs of delayed action and to cope with uncertainty about the outcome of future climate negotiations. By contrast, failing to curb emissions of greenhouse gases in the short term imposes rapidly increasing additional costs of compliance.

Rabl and van der Zwaan (2009) describe an unconventional framework that allows evaluating the benefit of reducing uncertainties about climate damage and emissions abatement costs. They analyze climate change with a strongly reduced cost-benefit model that minimizes the sum of discounted annual abatement plus damage costs. Their method is simpler than traditional models with the same purpose, and thus permits a more transparent sensitivity study with respect to the uncertainties of all parameters involved. They find an optimal stabilized emission level of $8.0 \mathrm{GtCO}_{2} / \mathrm{yr}$ and corresponding atmospheric $\mathrm{CO}_{2}$ concentration of close to $500 \mathrm{ppmv}$. Even under large parameter variations the optimal emission level remains within a remarkably narrow range. Also the social cost penalty turns out to be rather insensitive to errors.

Despite the many uncertainties about the impact of technological change on mitigation costs, there is wide agreement that technological innovation is an important condition to foster the needed de-carbonization of the economy. The contribution by Greaker and Pade (2009) deals with the crucial issue how to design a climate policy that achieves the optimal level of innovation. They investigate the relationship between emission taxes and technological change by modelling innovation activity explicitly. In their theoretical model both the amount of R\&D and the level of $\mathrm{CO}_{2}$ abatement are decided in a decentralized way by the market in response to an emission tax. Several distinct market failures for new innovations are introduced, such as insufficient patent protection and intertemporal knowledge spill-overs. They find that under some circumstances carbon taxes need to be higher when technological change is simulated endogenously in comparison to the exogenous representation of technical innovation.

Among the many technologies available in the climate mitigation portfolio, $\mathrm{CO}_{2}$ capture and storage (CCS) is considered an important low carbon technology, because it allows the continuation of using fossil fuels while reducing the corresponding $\mathrm{CO}_{2}$ emissions. CCS may therefore play an important role, especially in countries that heavily rely on coal for the generation of electricity, such as China and India. Lackner and Brennan (2009) point out that in order to meet the challenge of climate change while allowing for continued economic development, the world will have to adopt a net zero carbon energy infrastructure. Due to the world's large stock of lowcost fossil fuels, there is strong motivation to explore the opportunities for capturing the $\mathrm{CO}_{2}$ that is produced during the combustion of fossil fuels and keeping it out of the atmosphere. They argue that three distinct sets of technologies are needed to allow for the climate-neutral use of fossil fuels: (1) capture of $\mathrm{CO}_{2}$ at concentrated sources like electric power plants, future hydrogen production plants and steel and cement plants; (2) capture of $\mathrm{CO}_{2}$ from the air; and (3) the safe and permanent storage of $\mathrm{CO}_{2}$ away from the atmosphere. The accounting of stored $\mathrm{CO}_{2}$ could potentially be realised by isotopic ${ }^{14} \mathrm{C}$ monitoring.

Baker et al. (2009) acknowledge the inherent uncertainties affecting the relationship between R\&D investments and technical change. They present the results of an expert elicitation on the prospects for technical change in the use of CCS. They find a significant amount of disagreement between experts, even over the most mature version of this technology. The disagreement proves most pronounced with regards 
to cost estimates. The expert consultation results are incorporated in an integrated assessment model of climate change as probabilistic information about the impacts of $R \& D$ investments on the costs of emission abatement. They conclude that more information about the technical and societal potential for CCS needs to be gathered, while cost differences among the different capture technologies play a relatively small role.

Deforestation and forest degradation are currently responsible for approximately $18 \%$ of global $\mathrm{CO}_{2}$ emissions, and a third of historic emissions. Hence $\mathrm{CO}_{2}$ sequestration through land use, land use changes and forestry (LULUCF) is a hotly debated topic in international climate change negotiations. The last two papers deal with several fundamental issues related to biological sequestration, such as leakage, permanence and storage dynamics. Sun and Sohngen (2009) examine the controversial role of forest set-asides in protecting forests from timber harvesting and land-use conversion, since these may lead to large leakage of $\mathrm{CO}_{2}$. Using a global land use and forestry model, they analyse alternative policy scenarios where set-asides with and without other options for $\mathrm{CO}_{2}$ sequestration are credited for deviations from a baseline. They show that set-aside policies possess clear potential for $\mathrm{CO}_{2}$ sequestration: $106-128 \mathrm{GtC}$ by 2105 at a cost of up to $\$ 187 / \mathrm{tC}$. They also point out that in order to reduce leakage and maximize long-run $\mathrm{CO}_{2}$ removal from the atmosphere, set-aside policies should be complementary to a comprehensive forestry sequestration program that increases rotation ages and includes a wide range of other management options.

Caparros (2009) uses a theoretical framework for optimal biological sequestration as a response to carbon taxing. He extends an existing model, in which instantaneous sequestration of $\mathrm{CO}_{2}$ by forests is assumed, by accounting for the fact that trees need in reality decades or centuries to reach their maximum biomass capacity. This delay proves to have important implications for the optimal timing of reforestation: it needs to take place immediately following the imposition of a carbon tax. Furthermore, a faster increase of carbon prices can induce a reduction in the rate of reforestation. Such reduction may take place after an initial phase of increased reforestation, but also immediately, depending on the shape of the carbon price increase. The type of tree species and their growth rate also prove to be relevant, since they affect the land conversion rate.

We conclude by confirming that much progress has been achieved recently in the integrated assessment of climate change, to which we hope this special issue adds another set of new elements. A lot still needs to be researched, however-unlike some specialists seem to suggest-relative to the many aspects of climate change economics. On the damage side, climate targets require particular attention, while on the abatement side energy technologies need to be much further investigated. For all present and future climate mitigation technologies two drivers of technical change ought to be vigorously stimulated: fundamental research with regards to innovative concepts and practical implementation of existing clean options. CCS is undoubtedly an important mitigation technology, and probably inevitable, but large demonstration projects urgently need to be realized and further R\&D should be undertaken, notably regarding $\mathrm{CO}_{2}$ storage integrity and technology like air capture. Reducing emissions from deforestation and forest degradation-known as REDDshould also be an important contributor to controlling our climate, but there is lots left to be understood about the dynamics of corresponding carbon sequestration 
potentials and regarding policies designed to avoid deforestation, realize reforestation and stimulate optimal forestry management in view of maximizing long-run storage and minimizing leakage of $\mathrm{CO}_{2}$.

\section{References}

Baker E, Chon H, Keisler J (2009) Carbon capture and storage: combining economic analysis with expert elicitations to inform climate policy. Climatic Change (this issue)

Bosetti V, Carraro C, Sgobbi A, Tavoni M (2009) Delayed action and uncertain stabilisation targets: how much will climate policy cost? Climatic Change (this issue)

Caparros A (2009) Delayed carbon sequestration and rising carbon prices. Climatic Change (this issue)

Gore A (2007) Nobel peace prize lecture 2007. See nobelprize.org

Greaker M, Pade LL (2009) Optimal carbon dioxide abatement and technological change: should emission taxes start high in order to spur R\&D? Climatic Change (this issue)

Heal G (2009) The economics of climate change: a post-Stern perspective. Climatic Change (this issue)

IPCC (2007) Intergovernmental panel on climate change, fourth assessment report. Cambridge University Press, Cambridge

Lackner K, Brennan S (2009) Envisioning carbon capture and storage: expanded possibilities due to air capture, leakage insurance, and C-14 monitoring. Climatic Change (this issue)

Rabl A, van der Zwaan BCC (2009) Cost-benefit analysis of climate change dynamics: uncertainties and the value of information. Climatic Change (this issue)

Stern N et al (2006) The economics of climate change: the Stern review. Cambridge University Press, Cambridge

Sun B, Sohngen B (2009) Set-asides for carbon sequestration: implications for permanence and leakage. Climatic Change (this issue) 